\title{
Density Functional Study of Hydrazine N-N Bond Cleaving on 3d Metal Surfaces
}

\author{
Fadjar Fathurrahman ${ }^{\mathrm{a}}$, Hideaki Kasai ${ }^{\mathrm{b}, \mathrm{c}, *}$ \\ ${ }^{a}$ Department of Precision Science \& Technology and Applied Physics, Graduate School of Engineering, Osaka University, Suita, Osaka \\ 565-0871, Japan \\ ${ }^{b}$ Insitute of Industrial Science, The University of Tokyo, Meguro-ku, Tokyo 153-8505, Japan \\ ${ }^{c}$ National Institute of Technology, Akashi, Japan
}

\begin{abstract}
Theoretical calculations based on dispersion-corrected density functional theory (DFT-D2) has been performed to investigate hydrazine adsorption and $\mathrm{N}-\mathrm{N}$ bond cleaving on closed packed surfaces of $3 d$ metals: $\mathrm{Fe}(110)$, $\mathrm{Co}(0001), \mathrm{Ni}(111), \mathrm{Cu}(111)$, and $\mathrm{Zn}(0001)$. The activation energies of $\mathrm{N}-\mathrm{N}$ bond cleaving of hydrazine on each surface are estimated using climbing-image nudged elastic band (CINEB) method. The results showed that the activation energies for this process have increasing trend from $\mathrm{Fe}(110)$ to $\mathrm{Zn}(0001)$. By examining the electronic structure of the adsorbed hydrazine, it is found that this trend is related to occupation of derived $6 \sigma^{*}$ orbitals. It is also found that approximate linear relationship between reaction energy and activation energy (the BrønstedEvans-Polanyi (BEP) relationship) holds for those surfaces.
\end{abstract}

Keywords: density functional theory, hydrazine, decomposition, $\mathrm{N}-\mathrm{N}$ bond cleaving

\section{Introduction}

Hydrazine $\left(\mathrm{N}_{2} \mathrm{H}_{4}\right)$ is an important inorganic chemical in various applications. In gas phase it has three conformations: anti, cis, and gauche as depicted in Figure 1. It is mainly used as propellant for rocket engines and satellites [1]. It is also used as reducing agent in chemical synthesis [2]. Recently, hydrazine has been investigated for hydrogen generation application $[3,4,5]$ and precious-metal-free direct hydrazine fuel cell $[6,7,8,9,10]$. Catalytic decomposition of hydrazine on solid surfaces is an important process in these applications. An atomistic view of this decomposition is desirable for optimization of the catalytic process.

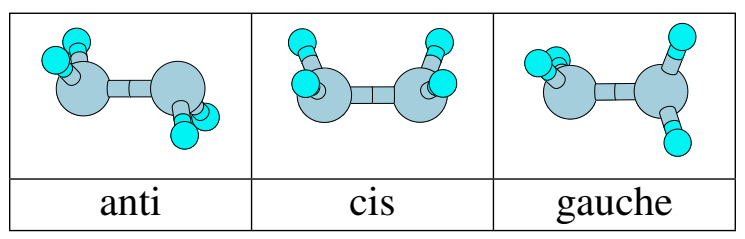

Figure 1: Conformations of hydrazine in gas phase

The decomposition of hydrazine gives nitrogen, hydrogen, and ammonia as products which stoichiometric

\footnotetext{
${ }^{*}$ Corresponding author

Preprint submitted to Elsevier

(C) 2015. This manuscript version is made available under the Elsevier user license http://www.elsevier.com/open-access/userlicense/1.0/
}

June 20, 2015 
amount may vary depending on the reaction conditions. The following reaction has been suggested to describe hydrazine decomposition [11]:

$$
3 \mathrm{~N}_{2} \mathrm{H}_{4} \rightarrow 4(1-x) \mathrm{NH}_{3}+(1+2 x) \mathrm{N}_{2}+6 x \mathrm{H}_{2}
$$

with parameter $x$ has value between 0 and 1. Most of the previous studies of catalytic decomposition of hydrazine have been focused on finding the reaction pathways using various experimental techniques (for examples: [12, 13, $14,15,16,17,18,19,20]$. Unfortunately, despite of those extensive studies, the reaction pathways of hydrazine decomposition are not convincingly established yet. Various theoretical studies of hydrazine interaction with solid surfaces also have been done. Most of these studies focus on adsorption process of hydrazine on clean transition metal surfaces such as $\mathrm{Cu}(111), \mathrm{Cu}(100), \mathrm{Cu}(110)$ [21], $\mathrm{Ni}(100)$ [22], $\mathrm{Pt}(111)$ [23], Ni(111) [24], $\mathrm{Co}(0001)$, and $\operatorname{Pd}(111)[25]$.

In gas phase dissociation energy of $\mathrm{N}-\mathrm{N}$ bond of hydrazine is about $2.96 \mathrm{eV}$ while that of $\mathrm{N}-\mathrm{H}$ is $3.73 \mathrm{eV}[1]$, so it is expected that $\mathrm{N}-\mathrm{N}$ bond cleaving is more favorable than $\mathrm{N}-\mathrm{H}$ bond cleaving. Recent computational studies have indeed shown that hydrazine's $\mathrm{N}-\mathrm{N}$ bond cleaving is favored over the first $\mathrm{N}-\mathrm{H}$ bond cleaving on $\operatorname{Ir}(111)$ [26] and $\operatorname{Rh}(111)[27]$.

In this article, a computational study based on density functional theory of $\mathrm{N}-\mathrm{N}$ bond cleaving of hydrazine:

$$
\mathrm{N}_{2} \mathrm{H}_{4} \rightarrow 2 \mathrm{NH}_{2}
$$

on close-packed surface (the most stable) of $3 d$ metals: $\mathrm{Fe}(110), \mathrm{Co}(0001), \mathrm{Ni}(111), \mathrm{Cu}(111)$, and $\mathrm{Zn}(0001)$ is presented. These surfaces are chosen mainly because of their simplicity and potential as non-precious-metal catalysts $[6,7,8]$. The main objective of this study is to find whether certain trends may be found in $\mathrm{N}-\mathrm{N}$ bond cleaving of hydrazine on these surfaces and to investigate electronic structure aspects of this process. The discussion in this article will be divided into two parts. The first part discusses the adsorption energies and geometries while the second part deals with the electronic structure of adsorbed hydrazine as its $\mathrm{N}-\mathrm{N}$ bond is cleaved.

\section{Methods}

The calculations were performed using density functional theory as implemented in Quantum Espresso [28] package. Ultrasoft pseudopotentials [29] were used to treat interaction between electron and ionic cores. Plane wave basis set with cutoff 30 Ry for wave function and 200 Ry for electronic density were used. The surfaces $\mathrm{Fe}(110), \mathrm{Co}(0001), \mathrm{Ni}(111), \mathrm{Cu}(111)$, and $\mathrm{Zn}(0001)$ were modeled using 3-layer slab and $3 \times 3$ supercell constructed using their respective lattice bulk constants. Comparison of adsorption energies obtained by using 4-layer shows that the trend of adsorption energy is similar to that obtained by using 3-layer slab model. During geometry optimization, atoms at the bottom layer were fixed while other atoms were allowed to relax in any directions. A 
vacuum layer of about $20 \AA$ and dipole correction have been used to eliminate the interaction between periodic image of slab. Brillouin zone sampling was done using $3 \times 3 \times 1$ Monkhorst-Pack grid. The PBE [30] exchangecorrelation functional has been used for all calculations. Recent studies [31, 32] showed that PBE functional gives balanced description of the bulk structure of various transition metal elements. Spin polarization has been included in all calculations. DFT-D2 method $[33,34,35]$ was used to account for dispersion force. The inclusion of DFT-D2 was found to be important in $\mathrm{Cu}$ surfaces[36] and is also expected to be important for $\mathrm{Zn}(0001)$ surface that is considered here. Nudged elastic band (NEB) [37] calculations were used to estimate activation energies of $\mathrm{N}-\mathrm{N}$ bond cleaving. The reaction path was discretized using 8 images. Climbing image version of NEB (CINEB) [38, 39] was used to improve the transition state search. Additional calculations of $\mathrm{N}-\mathrm{N}$ bond stretching of hydrazine in gas phase is done by Gaussian09 package [40] using basis set 6-31G(d,p) and B3LYP level theory. The resulting energy levels of hydrazine obtained using this setting is qualitatively similar to the ones obtained using plane wave calculation.

\section{Calculation results and analysis}

\subsection{Energetics and geometry}

In this article, adsorption energy $E_{\text {ads }}$ is calculated as

$$
E_{\mathrm{ads}}=E_{\mathrm{mol} / \mathrm{surf}}-E_{\mathrm{surf}}-E_{\mathrm{mol}}
$$

where $E_{\mathrm{mol} / \text { surf }}$ is total energy of hydrazine adsorbed on surface, $E_{\mathrm{surf}}$ is total energy of clean surface, and $E_{\mathrm{mol}}$ is total energy of gas phase hydrazine molecule in gauche conformation.

Hydrazine adsorbed molecularly in cis-like structure (which will also be designated as bri-A) has been used as initial geometry for CINEB calculation for all surfaces. For final structure, adsorption structure with two $\mathrm{NH}_{2}$ fragments adsorbed on two bridge sites is used for $\mathrm{Fe}(110), \mathrm{Co}(0001), \mathrm{Ni}(111)$, and $\mathrm{Cu}(111)$. For $\mathrm{Zn}(0001)$, adsorption structure with two $\mathrm{NH}_{2}$ fragments adsorbed on two top sites is used as final structure because it was found that potential energy surface near this structure is relatively flat. Except for $\mathrm{Zn}(0001)$ such ontop structure is not found by geometry optimization on other surfaces. Figure 2 and 3 give initial, final, and transition state structure found from CINEB calculations on $\mathrm{Ni}(111)$ and $\mathrm{Zn}(0001)$. It can be observed that the transition states for $\mathrm{N}-\mathrm{N}$ bond cleaving closely resemble initial structures, so they may be classified as early transition states.

The adsorption energies of these structures along with the activation and reaction energies for each surface are given in Table 1. The imaginary frequencies associated with $\mathrm{N}-\mathrm{N}$ bond stretch at the transition state are also

provided in Table 1. In Figure 4, adsorption energies of initial, transition, and final states are visualized. Except for $\mathrm{Zn}(0001)$, found to be exothermic process for all surfaces. The activation energy for this process has the lowest value for $\mathrm{Fe}(110)$ and highest for $\mathrm{Zn}(0001)$. 


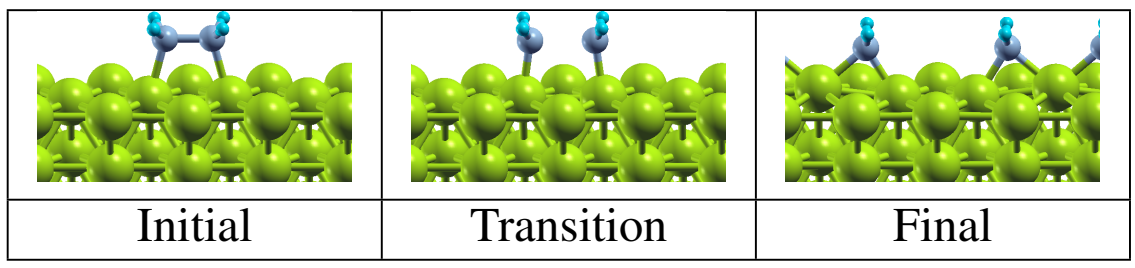

Figure 2: Initial, transition, and final structure for $\mathrm{N}-\mathrm{N}$ bond cleaving on $\mathrm{Ni}(111)$. Similar structures are also obtained for Fe(110), $\mathrm{Co}(0001)$, and $\mathrm{Cu}(111)$.

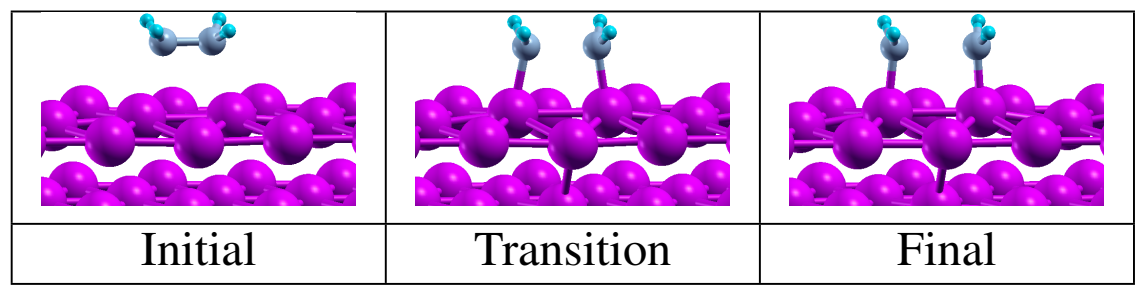

Figure 3: Initial, transition, and final structure for $\mathrm{N}-\mathrm{N}$ bond cleaving on $\mathrm{Zn}(0001)$.

As shown in Figure 5, the Brønsted-Evans-Polanyi relationship which is shown to hold for various systems $[41,42,43,44]$. can be established for $\mathrm{N}-\mathrm{N}$ bond cleaving of hydrazine. While the reaction energy $\Delta E$ is a good descriptor to predict activation energy, it is also possible that other descriptors such as adsorption energy of final product [45], i.e $E_{\mathrm{fin}}$, might be a better descriptor for predicting activation energy of $\mathrm{N}-\mathrm{N}$ bond cleaving of hydrazine. We are currently working to extend our investigation to other surfaces.

Table 1: Calculated adsorption energies of initial $E_{\mathrm{ini}}$, transition $E_{\mathrm{TS}}$, and final structure $E_{\mathrm{fin}} . \Delta E$ is calculated as $E_{\mathrm{fin}}-E_{\mathrm{fin}}$. All energies are given in $\mathrm{eV}$ and calculated relative to gas phase hydrazine in gauche conformation. The imaginary frequecies are given in $\mathrm{cm}^{-1}$

\begin{tabular}{|c|c|c|c|c|c|c|}
\hline Surface & $E_{\text {ini }}$ & $E_{\mathrm{TS}}$ & $E_{\text {fin }}$ & $\Delta E$ & $E_{\text {act }}$ & $v^{\mathrm{TS}}$ \\
\hline $\mathrm{Fe}(110)$ & -1.28 & -1.05 & -3.26 & -1.96 & 0.23 & $504.4 \mathrm{i}$ \\
$\mathrm{Co}(0001)$ & -1.47 & -1.08 & -2.83 & -1.36 & 0.39 & $337.0 \mathrm{i}$ \\
$\mathrm{Ni}(111)$ & -1.32 & -0.83 & -2.35 & -1.03 & 0.49 & $334.6 \mathrm{i}$ \\
$\mathrm{Cu}(111)$ & -0.94 & -0.35 & -2.03 & -1.09 & 0.59 & $516.8 \mathrm{i}$ \\
$\mathrm{Zn}(0001)$ & -0.29 & 0.62 & 0.42 & 0.71 & 0.91 & $168.1 \mathrm{i}$ \\
\hline
\end{tabular}

Two geometry quantities, i.e. distance between $\mathrm{N}-\mathrm{N}$ atom of hydrazine $d_{\mathrm{N}-\mathrm{N}}$ and distance between $\mathrm{N}$ atom of hydrazine and bonded surface atom $d_{\mathrm{N}-\mathrm{M}}(\mathrm{M}=\mathrm{Fe}, \mathrm{Co}, \mathrm{Ni}, \mathrm{Cu}$, or $\mathrm{Zn})$, are given in Table 2 and 3, respectively. It is observed that $d_{\mathrm{N}-\mathrm{N}}^{\mathrm{IS}}$ has increasing trend from $\mathrm{Fe}(110)$ to $\mathrm{Zn}(0001)$, with very close values obtained for $\mathrm{Co}(0001)$, $\mathrm{Ni}(111)$, and $\mathrm{Cu}(111) . d_{\mathrm{N}-\mathrm{N}}^{\mathrm{TS}}$ does not have similar trend as $d_{\mathrm{N}-\mathrm{N}}^{\mathrm{IS}}$, however the lowest value is also obtained for $\mathrm{Fe}(110)$ and highest value for $\mathrm{Zn}(0001)$. Meanwhile, $d_{\mathrm{N}-\mathrm{M}}^{\mathrm{S}}$ has almost the same trend as adsorption energy $E_{\text {ini. }}$. For all surfaces, $d_{\mathrm{N}-\mathrm{M}}^{\mathrm{TS}}$ is found to be shorter than $d_{\mathrm{N}-\mathrm{M}}^{\mathrm{IS}}$.

In order to find more insight to the $\mathrm{N}-\mathrm{N}$ bond cleaving process, the activation energy $E_{\text {act }}$ is analyzed by 


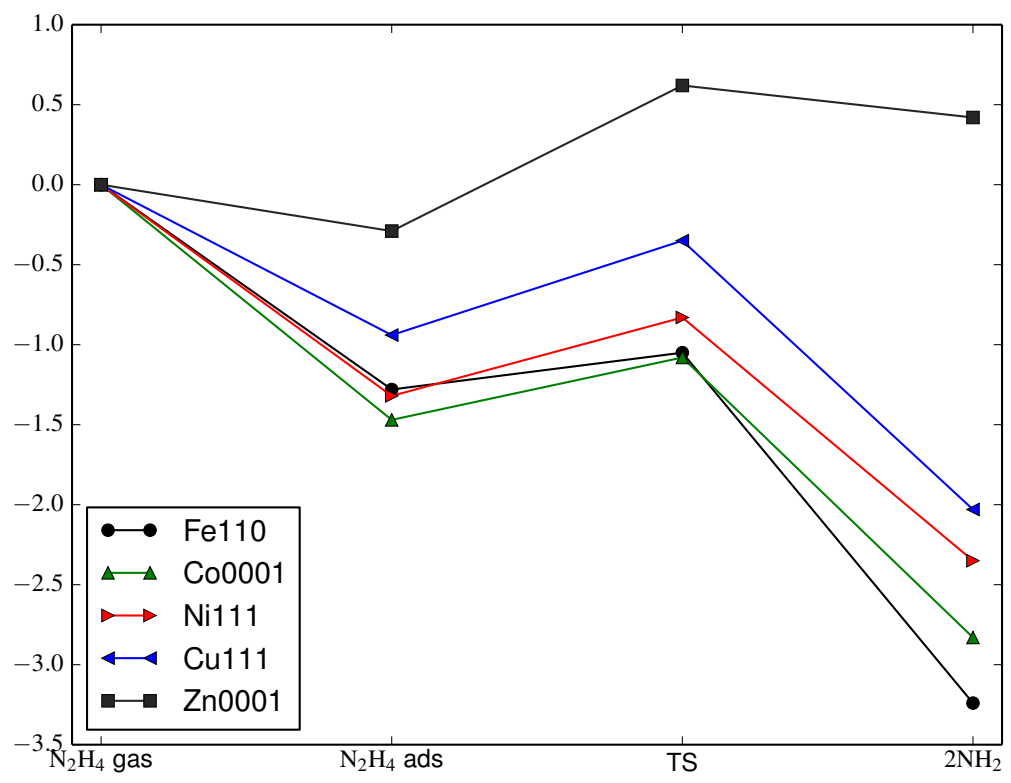

Figure 4: Energy diagram for $\mathrm{N}-\mathrm{N}$ bond cleaving of hydrazine

Table 2: $\mathrm{N}-\mathrm{N}$ bond distance of adsorbed hydrazine in initial and transition state structure. The difference is calculated as $\Delta d_{\mathrm{N}-\mathrm{N}}=$ $d_{\mathrm{N}-\mathrm{N}}^{\mathrm{TS}}-d_{\mathrm{N}-\mathrm{N}}^{\mathrm{IS}}$. All values are given in angstrom.

\begin{tabular}{|c|c|c|c|}
\hline Surface & $d_{\mathrm{N}-\mathrm{N}}^{\mathrm{IS}}$ & $d_{\mathrm{N}-\mathrm{N}}^{\mathrm{TS}}$ & $\Delta d_{\mathrm{N}-\mathrm{N}}$ \\
\hline $\mathrm{Fe}(110)$ & 1.486 & 1.803 & 0.317 \\
$\mathrm{Co}(0001)$ & 1.479 & 1.929 & 0.450 \\
$\mathrm{Ni}(111)$ & 1.479 & 2.046 & 0.567 \\
$\mathrm{Cu}(111)$ & 1.470 & 1.951 & 0.481 \\
$\mathrm{Zn}(0001)$ & 1.457 & 2.113 & 0.656 \\
\hline
\end{tabular}

decomposing it into several parts according to the following equation [46, 47, 27]:

$$
E_{\mathrm{act}}=E_{\mathrm{subs}}+E_{\mathrm{deform}}+\left(E_{\mathrm{A}}^{T S}+E_{\mathrm{B}}^{T S}-E_{\mathrm{int}}^{\mathrm{TS}}\right)-E_{\mathrm{AB}}^{\mathrm{IS}}
$$

This decomposition allows us to interpret activation energy as sum of various contributions from separate subsystems. $E_{\text {subs }}$ is calculated as total energy difference between surface only part of transition and initial geometry. $E_{\mathrm{deform}}$ is calculated similarly as $E_{\text {subs }}$ for $\mathrm{N}_{2} \mathrm{H}_{4} \cdot E_{\text {subs }}$ and $E_{\mathrm{deform}} E_{\mathrm{A}}^{\mathrm{TS}}$ and $E_{\mathrm{B}}^{\mathrm{TS}}$ are adsorption energies of fragment A and fragment $\mathrm{B}$ at the transition state. In the case of reaction $\mathrm{N}_{2} \mathrm{H}_{4} \longrightarrow 2 \mathrm{NH}_{2}, \mathrm{~A}$ and $\mathrm{B}$ are two different $\mathrm{NH}_{2}$ fragments. $E_{\text {int }}^{T S}$ is interaction energy between $\mathrm{A}$ and $\mathrm{B}$ at transition state geometry. Finally, $E_{\mathrm{AB}}^{\mathrm{IS}}$ is adsorption energy of hydrazine molecule at initial state geometry. Note that the adsorption energies $E_{\mathrm{A}}^{\mathrm{TS}}$ and $E_{\mathrm{B}}^{\mathrm{TS}}$ are calculated with respect to half of the total energy of gas phase hydrazine in gauche conformation.

The result of activation energy decomposition is given in Table 4. First, it is observed that $E_{\text {subs }}$ is relatively small (less than $0.05 \mathrm{eV}$ ) for all surfaces, except $\mathrm{Zn}(0001)$. This means that contribution of surface structure 


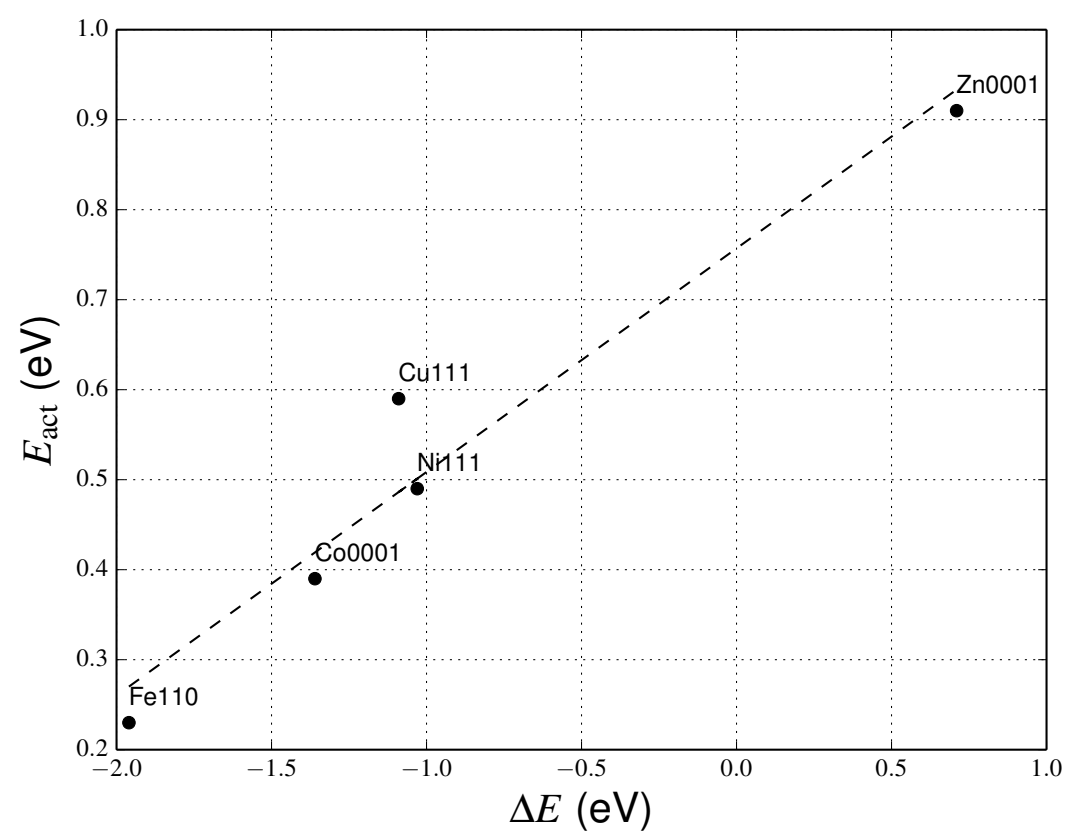

Figure 5: Brønsted-Evans-Polanyi relationship for $\mathrm{N}-\mathrm{N}$ bond cleaving of hydrazine on $3 d$ metal surfaces. The equation of the BEP line is $y=0.248 x+0.757$.

Table 3: $\mathrm{N}-\mathrm{M}$ bond distance $(\mathrm{M}=\mathrm{Fe}, \mathrm{Co}, \mathrm{Ni}, \mathrm{Cu}$, or $\mathrm{Zn})$ of adsorbed hydrazine in initial and transition state structure. The difference is calculated as $\Delta d_{\mathrm{N}-\mathrm{M}}=d_{\mathrm{N}-\mathrm{M}}^{\mathrm{TS}}-d_{\mathrm{N}-\mathrm{M}}^{\mathrm{IS}}$. All values are given in angstrom.

\begin{tabular}{|c|c|c|c|}
\hline Surface & $d_{\mathrm{N}-\mathrm{M}}^{\mathrm{IS}}$ & $d_{\mathrm{N}-\mathrm{M}}^{\mathrm{TS}}$ & $\Delta d_{\mathrm{N}-\mathrm{M}}$ \\
\hline $\mathrm{Fe}(110)$ & 2.137 & 1.992 & -0.145 \\
$\mathrm{Co}(0001)$ & 2.081 & 1.909 & -0.172 \\
$\mathrm{Ni}(111)$ & 2.026 & 1.873 & -0.153 \\
$\mathrm{Cu}(111)$ & 2.108 & 1.961 & -0.147 \\
$\mathrm{Zn}(0001)$ & 2.377 & 2.034 & -0.343 \\
\hline
\end{tabular}

changes to the activation energy is relatively small. The largest value of $E_{\text {subs }}$ is obtained for $\operatorname{Zn}(0001)$ which reflects the result that geometrical change of this surface is more noticeable compared to other surfaces (two $\mathrm{Zn}$ atoms which are bonded to $\mathrm{NH}_{2}$ go upward as compared to their positions in initial geometry). $E_{\text {deform }}$ is also found to be the largest for $\mathrm{Zn}(0001)$. The trend for this energy component is similar to the trend of $\Delta d_{\mathrm{N}-\mathrm{N}}$ : the greater change in $\mathrm{N}-\mathrm{N}$ bond length, the larger $E_{\text {deform }}$ (see Table 2). The next energy contributions are adsorption energies $E_{\mathrm{A}}^{\mathrm{TS}}$ and $E_{\mathrm{B}}^{\mathrm{TS}}$. Note that, because $\mathrm{N}-\mathrm{N}$ bond cleaving process on the surfaces studied here is symmetric, $E_{\mathrm{A}}^{\mathrm{TS}}$ and $E_{\mathrm{B}}^{\mathrm{TS}}$ will have the same values. The trend of this component is similar to the trend of $E_{\mathrm{act}}$. The stronger interaction between $\mathrm{NH}_{2}$ with surface: the more negative value of $E_{\mathrm{A}}^{\mathrm{TS}}$ ) the lower activation barrier. Adsorption energy of hydrazine at initial state $E_{\mathrm{AB}}^{\mathrm{IS}}$ has opposite effect with $E_{\mathrm{A}}^{\mathrm{TS}}$. For similar adsorption energy at the transition state, the stronger interaction of hydrazine with surface (more negative $E_{\mathrm{AB}}^{\mathrm{IS}}$ ) the larger activation energy. This is found to 
Table 4: Activation energy decomposition analysis for $\mathrm{N}_{2} \mathrm{H}_{4} \longrightarrow 2 \mathrm{NH}_{2}$

\begin{tabular}{|c|c|c|c|c|c|c||c|}
\hline Surface & $E_{\text {subs }}$ & $E_{\text {deform }}$ & $E_{\mathrm{A}}^{\mathrm{TS}}$ & $E_{\mathrm{B}}^{T S}$ & $-E_{\mathrm{AB}}^{I S}$ & $-E_{\text {int }}^{\mathrm{TS}}$ & $E_{\text {act }}$ \\
\hline $\mathrm{Fe}(110)$ & 0.01 & 0.68 & -1.02 & -1.02 & 1.28 & 0.30 & 0.23 \\
$\mathrm{Co}(0001)$ & 0.03 & 1.09 & -0.82 & -0.82 & 1.47 & -0.56 & 0.39 \\
$\mathrm{Ni}(111)$ & 0.03 & 1.45 & -0.62 & -0.62 & 1.32 & -1.07 & 0.49 \\
$\mathrm{Cu}(111)$ & 0.01 & 1.17 & -0.51 & -0.51 & 0.94 & -0.51 & 0.59 \\
$\mathrm{Zn}(0001)$ & 0.14 & 1.69 & 0.30 & 0.30 & 0.29 & -1.81 & 0.91 \\
\hline
\end{tabular}

be the case for $\mathrm{Fe}(110)$ and $\mathrm{Co}(0001)$ which are found to have similar $E_{\mathrm{A}}^{\mathrm{TS}}$. However, $E_{\mathrm{AB}}^{\mathrm{IS}}$ for $\operatorname{Co}(0001)$ is more negative which result in higher activation energy as compared to $\mathrm{Fe}(110)$. $E_{\mathrm{int}}^{\mathrm{TS}}$ mainly originate from interactions of nitrogen atoms of different $\mathrm{NH}_{2}$ fragments with surface. The largest value of $E_{\text {int }}^{\mathrm{TS}}$ is obtained for $\mathrm{Zn}(0001)$ which may be taken as a sign for strong attractive interaction between $\mathrm{N}-\mathrm{N}$ atoms of hydrazine.

\subsection{Electronic structure}

To investigate electronic structure aspect of $\mathrm{N}-\mathrm{N}$ bond cleaving of hydrazine we start by analyzing charge density difference $\rho_{\text {diff }}$ of adsorbed hydrazine. This quantity is calculated as:

$$
\rho_{\text {diff }}=\rho_{\mathrm{mol} / \mathrm{surf}}-\rho_{\mathrm{mol}}-\rho_{\text {surf }}
$$

where $\rho_{\mathrm{mol} / \text { surf }}$ is the charge density of hydrazine adsorbed on surface, $\rho_{\mathrm{mol}}$ and $\rho_{\text {surf }}$ denote charge density calculated separately with same atomic positions as found in adsorbed state for hydrazine and surface, respectively. Contour plots of $\rho_{\text {diff }}$ of adsorbed hydrazine at initial and transition state geometry are given in Figure 6 . It can be observed that the charge density difference of adsorbed hydrazine has similar features for all surfaces considered here. Along the bond between $\mathrm{N}$ atom of hydrazine and surface atom negative charge difference (depletion) region is observed at both edges (of $\mathrm{N}$ and surface atom) with positive charge difference (accumulation) region at the center of the bond. This positive charge difference is less pronounced on $\mathrm{Cu}(111)$ and $\mathrm{Zn}(0001)$ as compared to $\mathrm{Fe}(110), \mathrm{Co}(0001)$, and $\mathrm{Ni}(111)$ which reflects the magnitude of hydrazine adsorption energy. Meanwhile, along the $\mathrm{N}-\mathrm{N}$ bond at initial state, there is relatively small charge density difference which indicates that, in terms of charge density, the interaction between two $\mathrm{N}$ atoms in hydrazine is weaker than the interaction between the individual $\mathrm{N}$ atom and surface atom. However, at the transition state, there is substantial change in the charge density along $\mathrm{N}-\mathrm{N}$ bond of hydrazine. Charge depletion region is observed at the center of $\mathrm{N}-\mathrm{N}$ bond and accumulation region at both sides of the bond. The most pronounced charge accumulation around this area is observed for $\mathrm{Zn}(0001)$. This might be an indication that $\mathrm{N}-\mathrm{N}$ interaction of hydrazine at transition state is the strongest on $\mathrm{Zn}(0001)$ as also have been hinted by the $E_{\text {int }}^{\mathrm{TS}}$ term of Table 4 . 


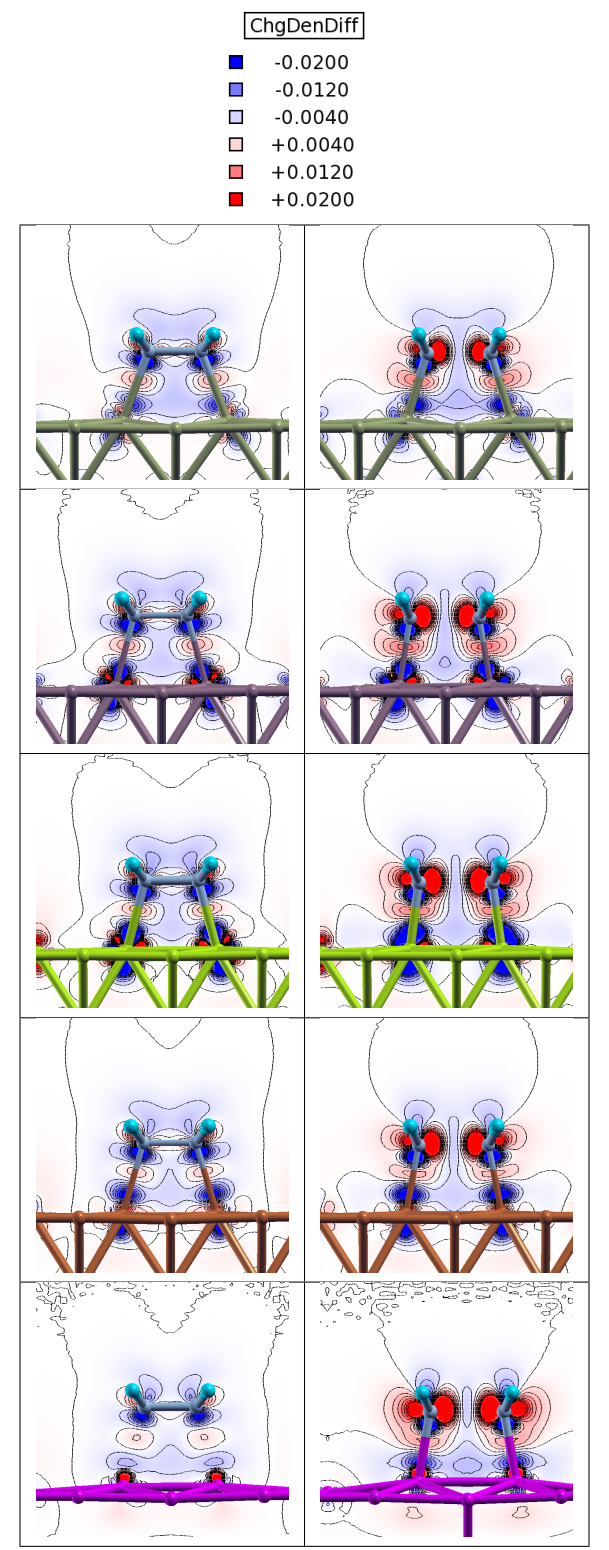

Figure 6: Contour plot of charge density difference of adsorbed hydrazine at initial (left) and transition geometry (right). From top to bottom: on $\mathrm{Fe}(110), \mathrm{Co}(0001), \mathrm{Ni}(111), \mathrm{Cu}(111)$, and $\mathrm{Zn}(0001)$.

To investigate the origin of $\mathrm{N}-\mathrm{N}$ activation trend across the investigated surface, molecular orbitals (MOs) of adsorbed hydrazine will be investigated. Before considering the MOs of adsorbed hydrazine, it is useful first to consider MOs of hydrazine in gas phase for cis conformation with normal $\mathrm{N}-\mathrm{N}$ bond length and the one with elongated $\mathrm{N}-\mathrm{N}$ bond. This is useful for investigating change of MOs during $\mathrm{N}-\mathrm{N}$ bond cleaving. Alternatively, we can also investigate the change of the molecular orbitals of hydrazine during by plotting the molecular orbital energy levels as function of $\mathrm{N}-\mathrm{N}$ bond length. In Figure 7 such plot is given. The MO energies of the elongated hydrazine is marked with the dashed lines in Figure 7. The comparison of MOs for both structures is given in Figure 8. Recall that hydrazine has 14 valence electrons which occupies 7 MOs. Figure 8 depicts the five highest occupied 
and two lowest unoccupied MOs along with their labels which will be used in this discussion. Note that the $4 \pi^{*}$ MO is the highest occupied molecular orbital (HOMO) while the $3 \pi$ MO is second highest occupied molecular orbital (HOMO-1). Visualization of molecular orbitals at the initial $\mathrm{N}-\mathrm{N}$ bond and the elongated hydrazine is given in Figure 7. From Figures 7 and 8, it can be seen that MOs of hydrazine and elongated hydrazine structure are very similar. However, two differences can be observed. First, for elongated cis $5 \sigma$ is higher in energy than $2 \pi$. Second, the unoccupied $6 \sigma^{*}$ also lower in energy, approaching HOMO. This pattern is also observed when $\mathrm{N}-\mathrm{N}$ bond cleaving of hydrazine happens on metal surfaces.

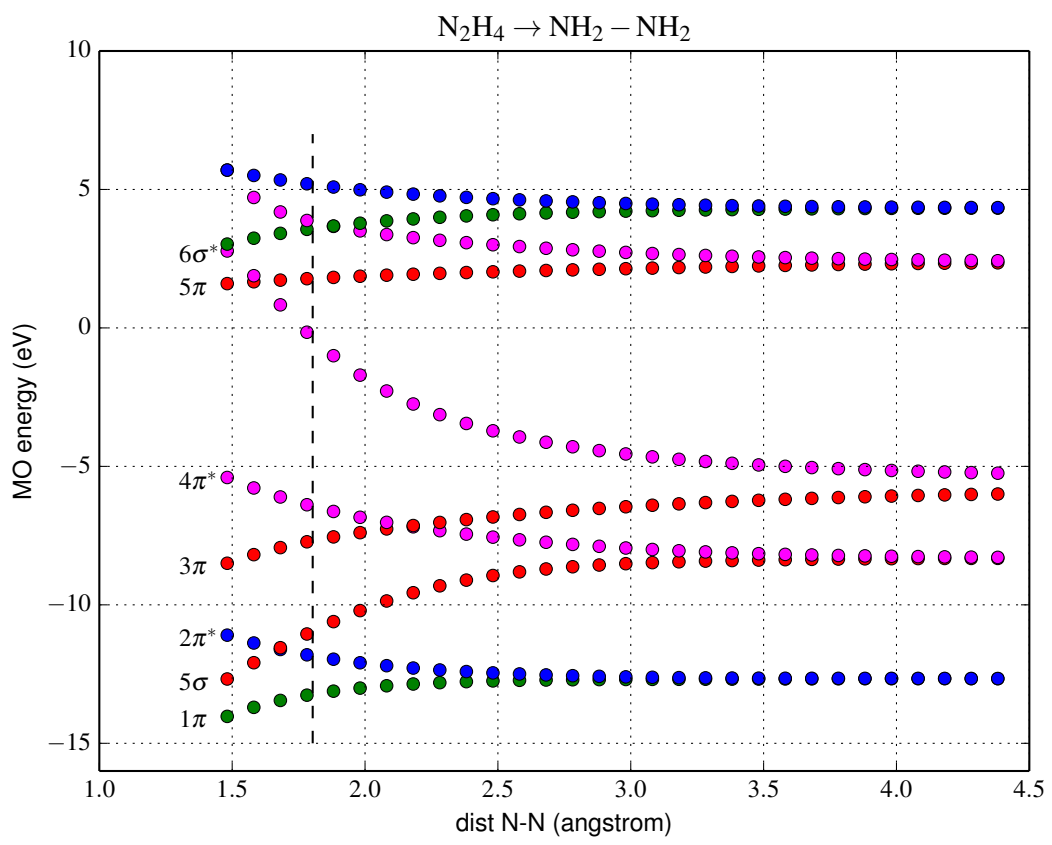

Figure 7: Change of molecular orbital energy levels of hydrazine as function of $\mathrm{N}-\mathrm{N}$ bond length. Hydrazine is initially at the cis structure. A vertical dashed line corresponds to the $\mathrm{N}-\mathrm{N}$ bond length of $1.8 \AA$, which is the shortest $\mathrm{N}-\mathrm{N}$ bond length among the transition states found in this work (see Table 2).

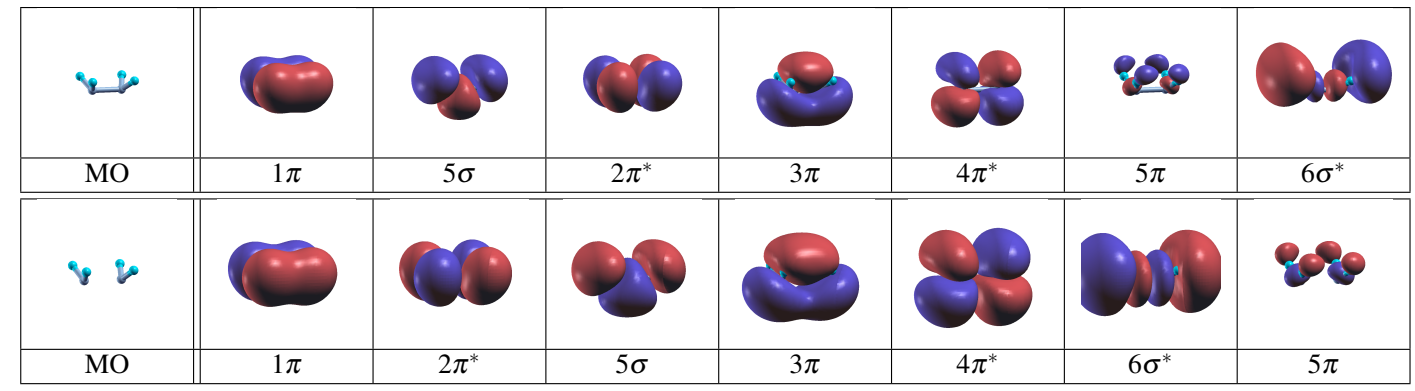

Figure 8: Gas phase molecular orbitals of hydrazine and hydrazine with elongated $\mathrm{N}-\mathrm{N}$ bond $\left(d_{\mathrm{N}-\mathrm{N}}=1.8\right)$. These MOs are ordered according to their energy levels: from left to right energy level become higher. Highest occupied molecular orbital for both case is the $4 \pi^{*}$ level.

In Figure 9 the electronic density of states (DOS) of initial and transition state projected to $s, p_{x}, p_{y}$, and $p_{z}$ orbitals of nitrogen atom are given. Zero energy levels for all plots are set to Fermi energy. At the initial state, 

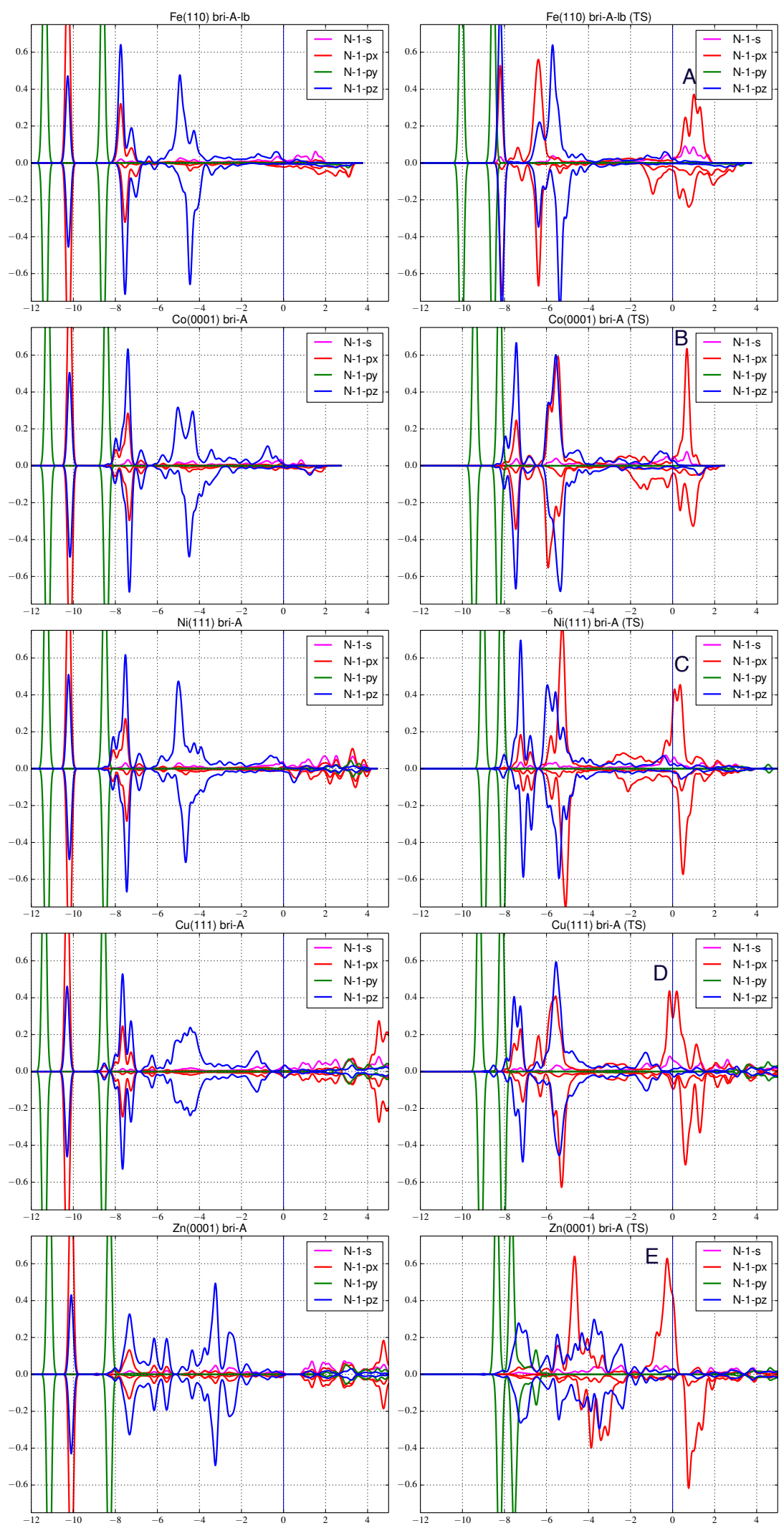

Figure 9: DOS projected on $\mathrm{N}$ atom of adsorbed hydrazine at initial (left) and transition geometry (right). Several peaks related to $6 \sigma^{*}$ derived orbitals at transition states have been marked by letters A-E. Visualization of such orbitals is given in Figure 11. 
three sharp peaks can be identified for all surfaces around the energy range of -12 to $-8 \mathrm{eV}$. Within the geometry that is used in this work, $\mathrm{N}-\mathrm{N}$ bond lies in $x$ axis, $1 \pi$ and $2 \pi^{*}$ will be composed almost entirely of nitrogen $p_{y}$ while $5 \sigma$ of nitrogen $p_{z}$ and $p_{x}$. Using this geometry, these three sharp peaks can be identified as derived orbitals (Kohn-Sham electronic states) from $1 \pi, 5 \sigma$, and $2 \pi^{*}$. These orbitals still retain their gas phase characteristics. At the transition state, these three peaks lie higher in energy with $5 \sigma$ peak located higher than $2 \pi^{*}$. This is similar to what was observed when comparing MOs of hydrazine and elongated hydrazine (see Figures 7 and 8). Peaks that are located higher in energy correspond to the derived orbitals due to interaction between HOMO-1 and HOMO with surface orbitals. These orbitals are dominated by contribution from $p_{z}$ orbitals of nitrogen. At transition state, HOMO will be shifted to lower energy, while HOMO-1 will be shifted to higher energy.

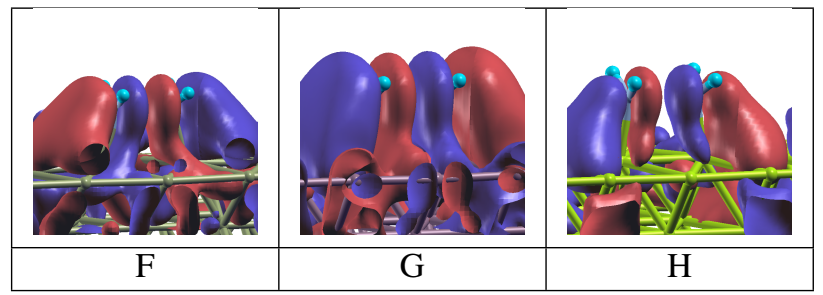

Figure 10: Visualization of Kohn-Sham orbitals which have $6 \sigma^{*}$ character of elongated hydrazine on $3 d$ surfaces, from left to right: Fe(110), $\mathrm{Co}(0001)$ and $\mathrm{Ni}(111)$. Aside from having $\mathrm{N}-\mathrm{N}$ antibonding character, these orbitals also have bonding The energy of these orbitals lie at the position indicated by letters F-H in Figure 9

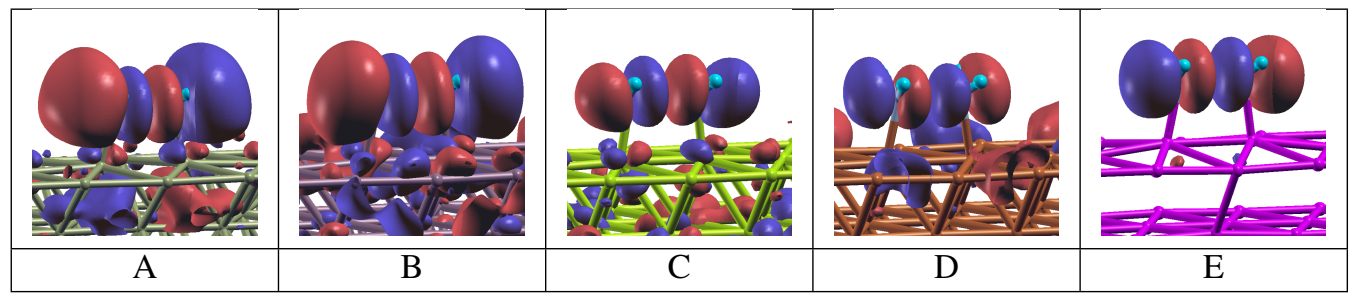

Figure 11: Visualization of Kohn-Sham orbitals which have $6 \sigma^{*}$ character of elongated hydrazine on $3 d$ surfaces, from left to right: $\mathrm{Fe}(110), \mathrm{Co}(0001), \mathrm{Ni}(111), \mathrm{Cu}(111)$, and $\mathrm{Zn}(0001)$. Aside from having $\mathrm{N}-\mathrm{N}$ antibonding character, these orbitals also have antibonding or nonbonding character with surface orbitals. As indicated by letters A-E in Figure 9, it can be seen that on $\mathrm{Fe}(110), \mathrm{Co}(0001)$, and $\mathrm{Ni}(111)$ these orbitals are located above Fermi level while for $\mathrm{Cu}(111)$ and $\mathrm{Zn}(0001)$ they are located below Fermi level.

The $\mathrm{N}-\mathrm{N}$ bond cleaving process is mainly caused by the population of $6 \sigma^{*}$-derived orbitals at transition state. These orbitals are dominated by nitrogen $p_{x}$ and have $\mathrm{N}-\mathrm{N}$ antibonding character. The interaction between gas phase $6 \sigma^{*} \mathrm{MO}$ of elongated hydrazine with surface $d$-orbitals ( $d$-band) will result in bonding and antibonding orbitals with respect to surface atom in the case of sufficiently strong coupling between these orbitals. The $6 \sigma^{*}$ derived bonding orbitals lie at lower energies and are readily occupied. Examples of such states are given in the Figure 10. On $\mathrm{Cu}(111)$ and $\mathrm{Zn}(0001)$ the interaction between $6 \sigma^{*}$ and $d$-orbitals due to large energy difference between them. However, the position of the peak of $6 \sigma^{*}$-derived antibonding states vary as we go from $\mathrm{Fe}(110)$ to $\mathrm{Zn}(0001)$. Examples of such states are given in Figure 11. For $\mathrm{Fe}(110)$, peaks that correspond to $6 \sigma^{*}$-derived 
antibonding states with surface atom lie above Fermi level. This results in stronger bonding between elongated hydrazine (transition state) with surface, thus more negative adsorption energy which will lead to lower activation energy. As we go down from $\mathrm{Fe}(110)$ to $\mathrm{Zn}(0001)$ these antibonding states lie lower in energy and are occupied by electrons. This will result in weaker interaction. Thus, from electronic structure perspective, the trend of activation energy for $\mathrm{N}-\mathrm{N}$ bond cleaving on the surfaces that are considered here can be attributed to this occupation of $6 \sigma^{*}$-derived orbitals.

\section{Conclusion}

In summary, $\mathrm{N}-\mathrm{N}$ bond cleaving process of hydrazine has been investigated on close-packed $3 d$ metal surfaces: $\mathrm{Fe}(110), \mathrm{Co}(0001), \mathrm{Ni}(111), \mathrm{Cu}(111)$, and $\mathrm{Zn}(0001)$. Going from $\mathrm{Fe}(110)$ to $\mathrm{Zn}(0001)$ activation energy is found to have increasing trend. The transition state for this process is found to closely resemble the structure of initial state. The present study also has shown that the Brønsted-Evans-Polanyi relationship holds for $\mathrm{N}-\mathrm{N}$ bond cleaving on $3 d$ metal surfaces that are considered. By analyzing the orbitals of adsorbed hydrazine it is found that the trend of activation energy is related to the occupation of $6 \sigma^{*}$-derived orbitals of the elongated hydrazine (the transition state). On the surface where the interaction of $6 \sigma^{*}$ orbital of the transition state is strong, the $6 \sigma^{*}$-derived bonding orbitals will be occupied and the derived antibonding orbitals will be unoccupied. However, on the surface where the interaction of $6 \sigma^{*}$ orbital of the transition state is weak, the antibonding (or nonbonding) orbitals will be occupied and this will result in more positive adsorption energy of the transition state. This will eventually lead to higher activation energy for $\mathrm{N}-\mathrm{N}$ bond cleaving.

\section{Acknowledgment}

Some of the numerical calculations presented here were done using the computer facilities at the following institutes: CMC (Osaka University), ISSP, KEK, NIFS, and YITP. This work is supported in part by: MEXT Grant-inAid for Scientific Research on Innovative Areas Program (2203-22104008) and Scientific Research (A)(26248006); JST ALCA Program "Development of Novel Metal-Air Secondary Battery Based on Fast Oxide Ion Conductor Nano Thickness Film"; JSPS Core-to-Core Program "A. Advanced Research Networks: Computational Materials Design on Green Energy"; and the Osaka University Joining and Welding Research Institute Cooperative Research Program. Part of this work is supported by Daihatsu Motor Corporation.

\section{References}

[1] Y. Batonneau, C.J. Kappenstein, W. Keim. In G. Ertl, H. Knözinger, J. Weitkamp, editors, Handbook of Heterogeneous Catalysis. VCH Verlagsgesellschaft mbH, 2008. 
[2] A. Furst, R.C. Berlo, S. Hooton. Chem. Rev. 1965. 65(1):51.

[3] M. Zheng, R. Cheng, X. Chen, N. Li, L. Li, X. Wang, T. Zhang. Int. J. Hydrogen Energy 2005. 30(10):1081.

[4] S.K. Singh, X.B. Zhang, Q. Xu. J. Am. Chem. Soc. 2009. 131(29):9894.

[5] S.K. Singh, Q. Xu. Catal. Sci. Technol. 2013. 3:1889.

[6] K. Yamada, K. Yasuda, H. Tanaka, Y. Miyazaki, T. Kobayashi. J. Power Sources 2003. 122(2):132.

[7] K. Asazawa, K. Yamada, H. Tanaka, A. Oka, M. Taniguchi, T. Kobayashi. Angew. Chem. Int. Ed. 2007. 46(42):8024.

[8] K. Asazawa, T. Sakamoto, S. Yamaguchi, K. Yamada, H. Fujikawa, H. Tanaka, K. Oguro. J. Electrochem. Soc. 2009. 156(4):B509.

[9] A. Serov, C. Kwak. Appl. Catal., B 2010. 98(1-2):1.

[10] H. Yang, X. Zhong, Z. Dong, J. Wang, J. Jin, J. Ma. RSC Adv. 2012. 2:5038.

[11] L.F. Audrieth, B.A. Ogg. The Chemistry of Hydrazine. Wiley, 1951.

[12] K. Aika, T. Ohhata, A. Ozaki. J. Catal. 1970. 19:140.

[13] R. Contaminard, F. Tompkins. Trans. Faraday Soc. 1971. 67:545.

[14] R. Cosser, F. Tompkins. Trans. Faraday Soc.220. 1971. 67:526.

[15] J. Contour, G. Pannetier. J. Catal. 1972. 24:434.

[16] M. Grunze. Surf. Sci. 1979. 81(2):603 .

[17] R. Maurel, J. Menezo. J. Catal. 1978. 51:293.

[18] R. Dopheide, L. Schröter, H. Zacharias. Surf. Sci. 1991. 257(1-3):86 .

[19] X. Chen, T. Zhang, M. Zheng, Z. Wu, W. Wu, C. Li. J. Catal. 2004. 224:473.

[20] M. Zheng, X. Chen, R. Cheng, N. Li, J. Sun, X. Wang, T. Zhang. Catal. Commun. 2006. 7:187.

[21] T.D. Daff, D. Costa, I. Lisiecki, N.H. de Leeuw. J. Phys. Chem. C 2009. 113(35):15714.

[22] M.K. Agusta, M. David, H. Nakanishi, H. Kasai. Surf. Sci. 2010. 604(3-4):245 .

[23] M.K. Agusta, W.A. Dino, M. David, H. Nakanishi, H. Kasai. Surf. Sci. 2011. 605(15-16):1347 . 
[24] M.K. Agusta, H. Kasai. Surf. Sci. 2012. 606(7-8):766 .

[25] M.K. Agusta, H. Kasai. J. Phys. Soc. Jpn 2012. 81(12):124705.

[26] P.X. Zhang, Y.G. Wang, Y.Q. Huang, T. Zhang, G.S. Wu, J. Li. Catal. Today 2011. 165:80.

[27] Z. Deng, X. Lu, Z. Wen, S. Wei, Y. Liu, D. Fu, L. Zhao, W. Guo. Phys. Chem. Chem. Phys. 2013. 15:16172.

[28] P. Giannozzi, et. al. J. Phys. Condens. Matt. 2009. 21(39):395502.

[29] D. Vanderbilt. Phys. Rev. B 1990. 41:7892.

[30] J.P. Perdew, K. Burke, M. Ernzerhof. Phys. Rev. Lett. 1996. 77:3865.

[31] P. Janthon, S.M. Kozlov, F. Viñes, J. Limtrakul, F. Illas. J. Chem. Theory Comput. 2013. 9(3):1631.

[32] P. Janthon, S.A. Luo, S.M. Kozlov, F. Viñes, J. Limtrakul, D.G. Truhlar, F. Illas. J. Chem. Theory Comput. 2014. 10(9):3832.

[33] S. Grimme. J. Comput. Chem. 2006. 27:1787.

[34] V. Barone, M. Casarin, D. Forrer, M. Pavone, M. Sambi, A. Vittadini. J. Comput. Chem. 2009. $30: 934$.

[35] S. Grimme, J. Antony, S. Ehrlich, H. Krieg. J. Chem. Phys. 2010. 132:154104.

[36] S.S. Tafreshi, A. Roldan, N.Y. Dzade, N.H. de Leeuw. Surf. Sci. 2014. 622:1.

[37] H. Jónsson, G. Mills, K.W. Jacobsen. In B.J. Berne, G. Ciccotti, D.F. Coker, editors, Classical and Quantum Dynamics in Condensed Phase Simulations. World Scientific, 1998.

[38] G. Henkelman, B.P. Uberuaga, H. Jónsson. J. Chem. Phys. 2000. 113(22):9901.

[39] G. Henkelman, H. Jónsson. J. Chem. Phys. 2000. 113(22):9978.

[40] M.J. Frisch, G.W. Trucks, H.B. Schlegel, G.E. Scuseria, M.A. Robb, J.R. Cheeseman, G. Scalmani, V. Barone, B. Mennucci, G.A. Petersson, H. Nakatsuji, M. Caricato, X. Li, H.P. Hratchian, A.F. Izmaylov, J. Bloino, G. Zheng, J.L. Sonnenberg, M. Hada, M. Ehara, K. Toyota, R. Fukuda, J. Hasegawa, M. Ishida, T. Nakajima, Y. Honda, O. Kitao, H. Nakai, T. Vreven, J.A. Montgomery, Jr., J.E. Peralta, F. Ogliaro, M. Bearpark, J.J. Heyd, E. Brothers, K.N. Kudin, V.N. Staroverov, R. Kobayashi, J. Normand, K. Raghavachari, A. Rendell, J.C. Burant, S.S. Iyengar, J. Tomasi, M. Cossi, N. Rega, J.M. Millam, M. Klene, J.E. Knox, J.B. Cross, V. Bakken, C. Adamo, J. Jaramillo, R. Gomperts, R.E. Stratmann, O. Yazyev, A.J. Austin, R. Cammi, C. Pomelli, J.W. Ochterski, R.L. Martin, K. Morokuma, V.G. Zakrzewski, G.A. Voth, P. Salvador, J.J. Dannenberg, S. Dapprich, A.D. Daniels, O. Farkas, J.B. Foresman, J.V. Ortiz, J. Cioslowski, D.J. Fox. Gaussian09 Revision C.01. Gaussian Inc. Wallingford CT 2009. 
[41] H. Toulhoat, P. Raybaud. J. Catal. 2003. 216(1-2):63 .

[42] T. Bligaard, J. Nørskov, S. Dahl, J. Matthiesen, C. Christensen, J. Sehested. J. Catal 2004. 224(1):206 .

[43] C.A. Menning, J.G. Chen. J. Chem. Phys. 2008. 128(16).

[44] S.C. Huang, C.H. Lin, J.H. Wang. J. Phys. Chem. C 2010. 114(21):9826.

[45] J.L. Fajín, M.N.D. Cordeiro, F. Illas, J.R. Gomes. J. Catal. 2014. 313(0):24 . ISSN 0021-9517.

[46] Y. Cao, Z.X. Chen. Phys. Chem. Chem. Phys. 2007. 9:739.

[47] S. Li, X. Lu, W. Guo, H. Zhu, M. Li, L. Zhao, Y. Li, H. Shan. J. Organomet. Chem. 2012. 704:38. 


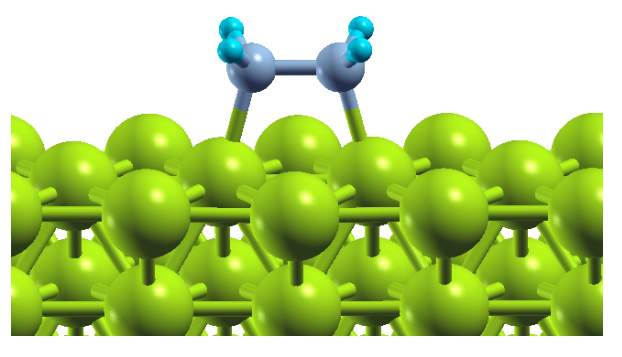

Initial

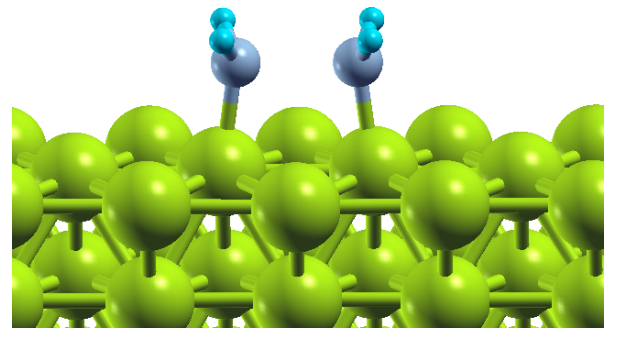

Transition

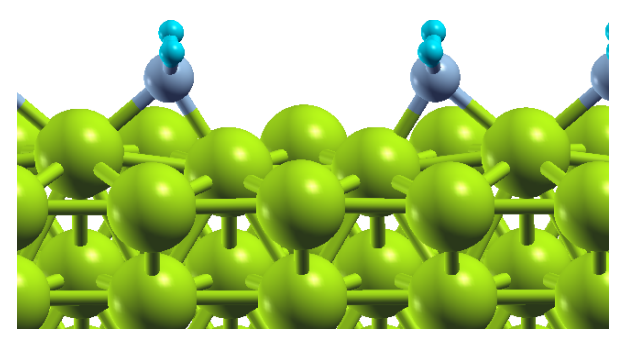

Final

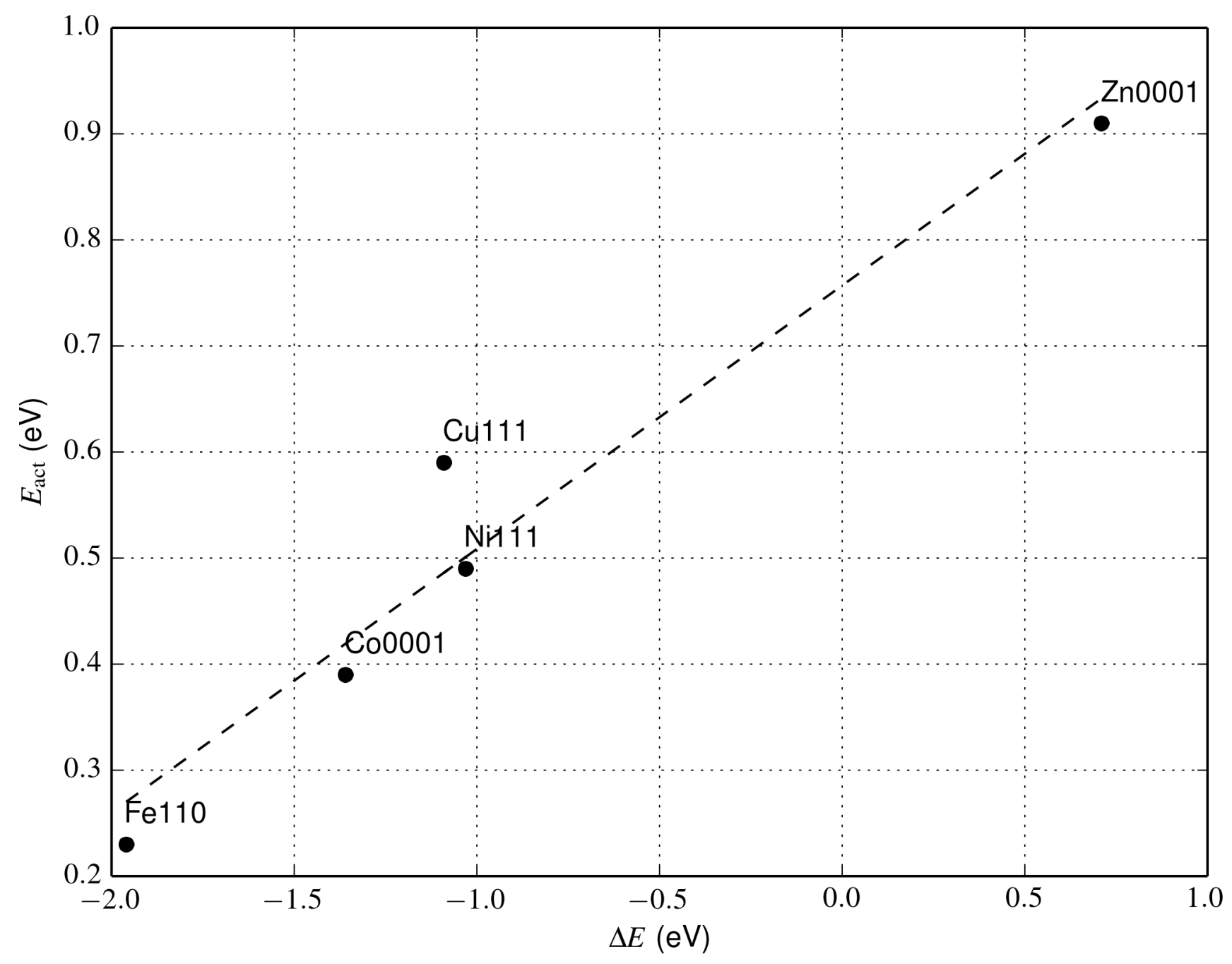

